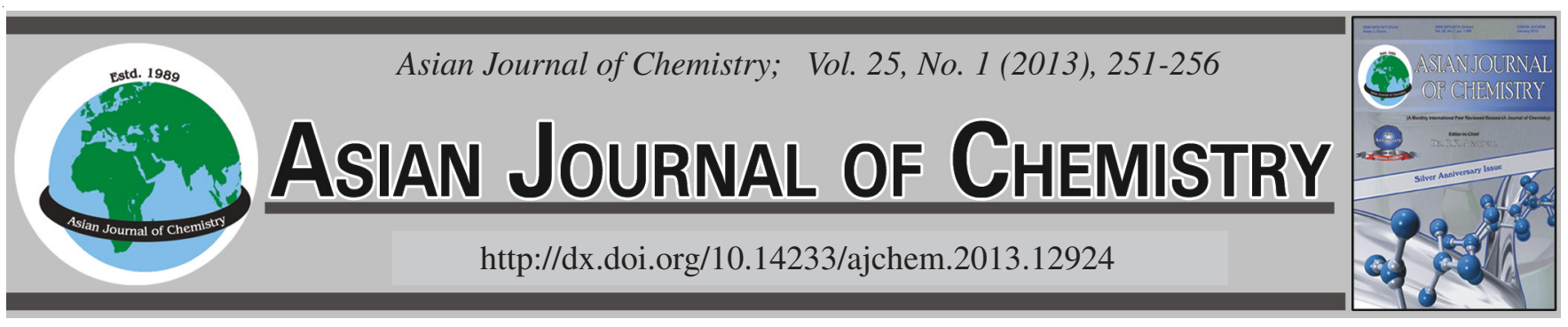

\title{
Evaluation of Enzymatic Removal of Cooling Water System Biofilm Using its Own Producer Bacteria
}

\author{
N. Ceyhan \\ Department of Biology, Faculty of Sciences, Mugla University, Mugla 48170, Turkey \\ Corresponding author: Fax: +90 252 2111472; Tel: +90 252 2113137; E-mail: nurceyhan@msn.com
}

(Received: 24 October 2011;

Accepted: 20 July 2012)

AJC-11857

\begin{abstract}
Biofilms can cause corrosion and seriously affect flow, pressure drop and the efficiency of heat transfer from metal surfaces. Cooling water systems, are essential parts in many industries, provide ideal aquatic environments for the microbiological fouling caused by biofilms. In these systems, the protection of bacteria by exopolysaccharide matrix construction in biofilm, bacterial resistance to biocides and their negative environmental effects are the main reasons to search alternative biofilm removal strategies. In this study, it was investigated that removal of cooling water system-biofilm through its own producer bacteria enzymatically. For this aim, 4 supernatant from biofilm bacteria, cultured onto polysaccharide substrates, were investigated for their enzymatic properties and their ability to remove a biofilm made with the same 4 bacteria. In conclusion, the best biofilm removal activities were obtained in gellan gum (91 $\pm 2 \%)$ and alginate $(62 \pm 3 \%)$ with Sphingomonas paucimobilissupernatant, xanthan gum $(88 \pm 6 \%)$ and xylan $(70 \pm 4 \%)$ with Bacillus sp. supernatant, alginate $(75 \pm 5 \%)$, gellan gum $(25 \pm 3 \%)$ and xylan $(14 \pm 3 \%)$ with Pseudomonas fluorescens supernatant, gellan gum (45 $\pm 7 \%)$ and xylan $(36 \pm 5 \%)$ with Aeromonas caviae supernatant. This study is interesting in aspect that the own producer enzymes may dislodge biofilm by degrading the exopolysaccharide matrix and data showed that the biofilm was removed by its own producers via polysaccharases to attack to various polysaccharide substrates, for control and disinfection practices of cooling water systems.
\end{abstract}

Key Words: Cooling water systems, Biofilm bacteria, Biofilm removal, Polysaccharide degrading enzymes, Exopolysaccharide degradation.

\section{INTRODUCTION}

Biofilms are communities of microorganisms, which develop on surfaces in natural and artificial environments ${ }^{1,2}$. Under certain conditions, free-floating planktonic bacteria initially attach reversibly to solid surfaces or adhere to each other (coaggregate) at surface interfaces (i.e. air-water) through weak interactions via bacterial components (e.g., fimbriae) and adhesion molecules ${ }^{3,4}$. The extracellular matrix components act as a kind of glue to more firmly attach the bacteria (sessile) to the surface, leading to the formation of structured microcolonies and biofilm accumulation ${ }^{5,6}$. The polymicrobial (multiple bacterial species) nature of biofilms provides shared defensive advantages, such as secretion of proteins that provide antimicrobial resistance to neighbouring bacterial species in the biofilm,or secretion of exopolysaccharides (EPS) that shield the biofilm community from penetration of antimicrobials ${ }^{7,8}$. In particular niches of the biofilm, local limitations of nutrients and oxygen may provide growth advantages to facultative anaerobes, or even strict anaerobes ${ }^{7}$. In other niches of the biofilm, some bacteria essentially stop growing and become quiescent. The reduced metabolic activity of the quiescent bacteria is one mechanism that is thought to contribute to the greatly increased tolerance to antimicrobial agents $^{9,10}$. Compared to planktonic (free-floating) bacteria, coaggregated-surface attached (sessile) microcolonies of bacteria in biofilms have enhanced resistance to killing by antimicrobial agents, such as biocides ${ }^{11}$. Therefore, microbial biofilms and corrosion in cooling water systems are the most common problems that damage expensive equipment, cause loss of production and increase maintenance costs ${ }^{12}$.

Cooling water systems are heat rejection devices used in industrial settings to efficiently cool building water systems without the use of refrigerants ${ }^{13}$. In essence chemical control generally involves the use of biocides to kill the microorganisms in the cooling water, or biostats to reduce their activity ${ }^{14,15}$. Many bacteria can develop a potential tolerance to an applied biocide and its use is becoming severely restricted on account of its detrimental effects on the qualityof the water discharged back to the natural environment from where it was abstracted and its effect on other living creatures, including humans ${ }^{16}$. Due to these negative impacts of biocides, prevention of biofilm formation by alternative enzymatic strategies may be treatment to move biofilm damages in cooling water systems. Nowadays 
it is obvious that enzymes are used as key active components in many cleaning agents, disinfectants and detergents ${ }^{17,18}$.

Less is known about the interactions between biofilm exopolysaccharides and enzymes but generally polysaccharide-degrading enzymes (polysaccharases = polysaccharide hydrolases (EC 3.2.1.-) and polysaccharide lyases (EC 4.2.2.-) and to a more limited extent proteases (EC 3.4.-), will disrupt the exopolysaccharides structure ${ }^{19,20}$. Such enzymes include alginate lyases, gellan lyase, pectate lyase, xanthan lyase, heparinase, chondroitinase and a number acting on various other bacterial exopolysaccharidess ${ }^{21}$.

Microorganisms can secrete these enzymes to degrade the exopolysaccharides matrix when their microenvironment becomes adverse e.g. when the nutrient supply becomes exhausted, allowing them to escape ${ }^{22}$. However the effect of any one enzyme degrading any one exopolysaccharides will depend on other exopolysaccharides in the biofilm. Thus degrading exopolysaccharides from the biofilm can result in the release of cells of one species but this may actually enhance growth of other species present in the biofilm. In fact enzymatic treatment can either strengthen or weaken the exopolysaccharides structure depending on the mode of action on individual exopolysaccharides and the role that exopolysaccharides provides in the biofilm ${ }^{23}$. Nevertheless, it's surprising that there are few studies on enzymatic elimination of biofilms ${ }^{24-26}$. When focusing on degradation organic compounds involved in biofilm, enzymes of biofilm bacteria, such as hydrolases and lyases, seem to be good antibiofilm agent candidates due to the fact that they are (a) already synthesized by its own biofilm producer bacteria; (b) biodegradable; (c) weak toxic, contrary to oxidase enzymes or nontoxic for environment ${ }^{27}$.

The present work is different from previous studies with aspect of enzymatic removal of biofilm in cooling water system in the first time and moreover enzyme supernatants from own producer bacteria of biofilm were used for this objective. Thus, the key point for practice is to destroy of microbial biofilms through the development of appropriate enzymes attacking to exopolysaccharides in biofilm structure.

\section{EXPERIMENTAL}

Bacteria: This study was performed using the heterotrophic bacteria isolated from biofilm layers of cooling water system of a petrochemical industry (Izmir, Turkey) $)^{15}$. Four bacteria were selected for this study, because they were the most exopolysaccharides producing biofilm bacteria according to these researchers. Pseudomonas fluorescens, Sphingomonas paucimobilis, Aeromonas caviae, Bacillus sp. For tests, they were routinely activated in NA (Nutrient Agar) (Merck1.05450) slants at $30{ }^{\circ} \mathrm{C}$ overnight. Samples from those cultures, were analyzed and stored at $-4{ }^{\circ} \mathrm{C}$.

Bacterial supernatants and culture conditions: The bacteria were grown at $30{ }^{\circ} \mathrm{C}$ for $72 \mathrm{~h}$ under shaking (200 $\mathrm{rpm}$ ) in $500 \mathrm{~mL}$ flasks containing $150 \mathrm{~mL}$ of YNB (Yeast Nitrogen Base) (a basal medium without carbon source) (Difco-239210). Two carbon sources were added $0.2 \%$ glucose as growth initiator and $0.8 \%$ of one of the following polysaccharides: sodium alginate (sodium alginic acid) from brown algae (Sigma-71238), xylan from beech wood (Sigma$\mathrm{X} 4252$ ), gellan gum from Sphingomonas elodea (CP Kelco) and xanthan gum from Xanthomonas campestris (CP Kelco).

The liquid cultures were assayed for amount of bacterial biomass every $8 \mathrm{~h}$. The biomass was separated by centrifugation of the broth at $15000 \times \mathrm{g}^{28}$; its weight, obtained by drying it at $80^{\circ} \mathrm{C}$ for $48 \mathrm{~h}$, was used to measure bacterial growth. Supernatants were frozen until use. All cultures were run in triplicate.

Formation of biofilm: Four of bacterial cell suspensions $(100 \mu \mathrm{L})$ containing $\mathrm{ca} .5 \times 10^{7}$ cells $\mathrm{mL}^{-1}$ in tryptone soya broth (TSB) (Oxoid CM0989, pancreatic digest of casein 17.0 $\mathrm{g} / \mathrm{L}$, papaic digest of soybean meal $3.0 \mathrm{~g} / \mathrm{L}$, sodium chloride $5.0 \mathrm{~g} / \mathrm{L}$, dipotassium hydrogen phosphate $2.5 \mathrm{~g} / \mathrm{L}$, glucose 2.5 $\mathrm{g} / \mathrm{L}$, bile salts $1.5 \mathrm{~g} / \mathrm{L}$, distilled water 11$)(\mathrm{pH} 7.4 \pm 0.2)$ were prepared as a mixture and used as biofilm starter culture. The cooling water system was made of stainless steel material, so biofilms were developed on stainless steel slides $(4.5 \times 1.5$ $\left.\mathrm{cm}^{2}\right)$ in the study. The slides were roughened using emery paper and sterilized before use by autoclave. Slides were placed to a sterile humidified cabinet to provide the conditions of the cooling system and continously recirculated by $500 \mathrm{~mL}$ of the biofilm growth medium (TSB) as equivalent to the entering organic materials into cooling system. These were left to grow at $30^{\circ} \mathrm{C}$ for $72 \mathrm{~h}$ for cell adhesion ${ }^{13,18}$.

Enzyme assays: Extracellular protease and polysaccharase activities in culture supernatants were evaluated for biofilm removal. All enzymatic activities were determined at $30{ }^{\circ} \mathrm{C}$. Alginate lyase, xylanase, gellan lyase, xanthan lyase were determined by measuring the release of reducing sugars from alginate, xylan, gellan and xanthan, respectively, by dinitrosalicylic acid method as described by Sahoo et al. ${ }^{29}$. One unit (U) of alginate lyase, xylanase, gellan lyase, xanthan lyase activity was defined as the amount of enzyme that produced reducing sugars corresponding to $1 \mu \mathrm{mol}$ of xylose or glucose equivalents from alginate, xylan, gellan and xanthan per minute, respectively, under the assay condition.

Protease activity was assayed using azocasein as described by Tomarelli et $a l^{30}{ }^{30 x c e p t ~ t h a t ~ t h e ~ e n z y m e ~ a c t i v i t i e s ~ w e r e ~}$ determined at $30^{\circ} \mathrm{C} .200 \mu \mathrm{L}$ of bacterial supernatants as enzyme source was incubated at $30{ }^{\circ} \mathrm{C}$ with $2 \%$ (w/v) azocasein in phosphate buffer of $\mathrm{pH} 8.15$ at different incubation times from 3 to $12 \mathrm{~min}$. The enzymatic activity was stopped by adding $10 \%$ trichloroacetic acid. The absorbance of enzymatically hydrolyzed casein was determined at $450 \mathrm{~nm}$. One unit of protease activity (U) was defined as the amount of enzyme required to produce an absorbance unit change per minute at $30{ }^{\circ} \mathrm{C}$ at $\mathrm{pH} 8.15$.

The enzymes-containing supernatants were decanted and stored at $-20{ }^{\circ} \mathrm{C}$ for further analysis. In all cases, the average value from three replicates and standard deviation (SD) were calculated.

Removal of biofilm: In the study, the adherent-living biomass (sessile) on the coupons were regarded as cell counts of biofilms (Cell counts-Biofilm) in this study. After every $8 \mathrm{~h}$, sessile bacteria were scraped off the slides using MicroAlpha swabs (Texwipe) and resuspended in $1.5 \mathrm{~mL}$ of $0.9 \%$ solution of $\mathrm{NaCl}$ by vortexing $(30 \mathrm{~s})^{31}$. After vortexing, slides were discarded and cells were centrifugally separated at $12,000 \mathrm{xg}$ at $4{ }^{\circ} \mathrm{C}$ for $0.5 \mathrm{~h}$. 
The cells were placed in $250 \mathrm{~mL}$ of tryptone soya broth and the resulting attached cell suspension, which was later on also used for preenrichment for cells, was thoroughly shaken and decimal dilutions were immediately prepared with sterile $0.1 \%$ peptone water. Dilutions were plated using tryptone soya agar (TSB + 1.5\% Agar) $(\mathrm{pH} 7.4 \pm 0.2)$ for biofilm forming total viable counts and incubated at $30^{\circ} \mathrm{C}$ for $48 \mathrm{~h}$. After the incubation period, colonies were enumerated the number of biofilm forming cells. The difference between initial cell numbers and cell numbers at the end of each $8 \mathrm{~h}$ was evaluated as biofilm removal and then, these values were calculated as the percentage of biofilm removal.

Sterile tryptone soya broth was used for the control. Three assays were performed in each experiment.

Data analysis: All experiments were performed at least three times $(n=3)$. An average of three replicates and standard deviation from mean value were determined. Statistical analysis with $p$ value was determined for the percentage calculation of biofilm removal. Data were analyzed using the $t$-test seeking at least $95 \%$ confidence.

\section{RESULTS AND DISCUSSION}

Here, cooling system-biofilm removal by bacterial cultures, which are own producers of biofilm with activities of their enzymes on polysaccharides similar to exopolysaccharides matrix have been investigated. Biomass production examined in the culture supernatants taken along the $72 \mathrm{~h}$ cultures of $P$. fluorescens including as carbon source either alginate, gellan gum and xylan are shown in Fig. 1a. In the same way, corresponding to $S$. paucimobilis cultures on alginate and gellan gum, $A$. caviae cultures on gellan gum and xylan, Bacillus sp. cultures on xylan and xanthan gum, are in Fig. 1(b), (c) and (d), respectively.
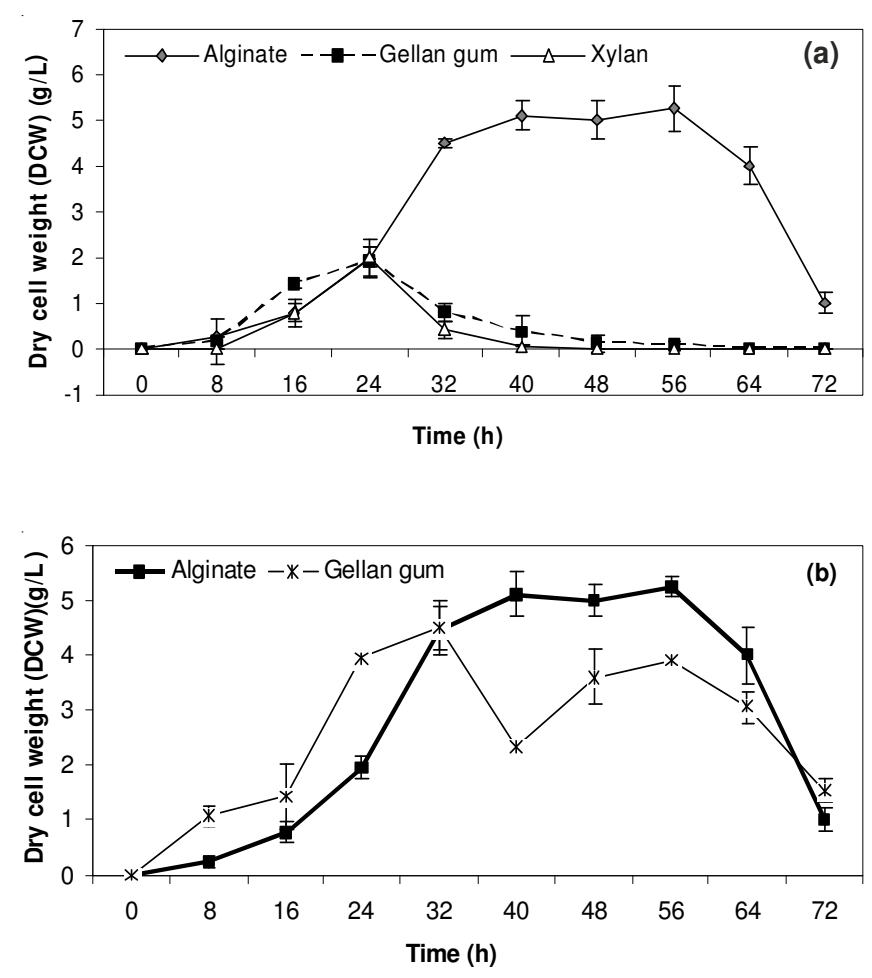
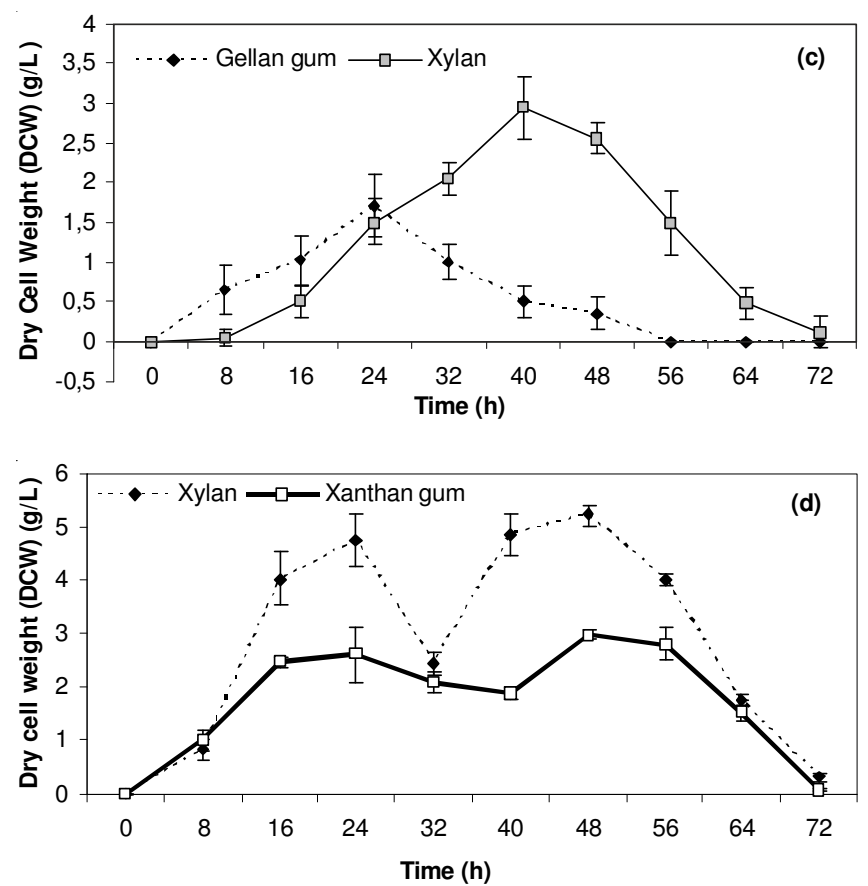

Fig. 1. Biomass production of bacteria cultures from $P$. fluorescens culture on alginate, gellan gum and xylan (a), S. paucimobilis culture on alginate and gellan gum (b), A. caviae culture on gellan gum and xylan (c), Bacillus sp. culture on xylan and xanthan gum (d). Bars indicate standard deviations $(n=3)$

Protease activities: Protease activities from bacterial cultures were given in Fig. 2. Proteinase activity did not change significantly along growth in any of the four bacterial cultures, staying always below $8.5 \mathrm{U} / \mathrm{mL}$. The highest values were detected at cultures on alginate by $P$. fluorescens (Fig. 2).

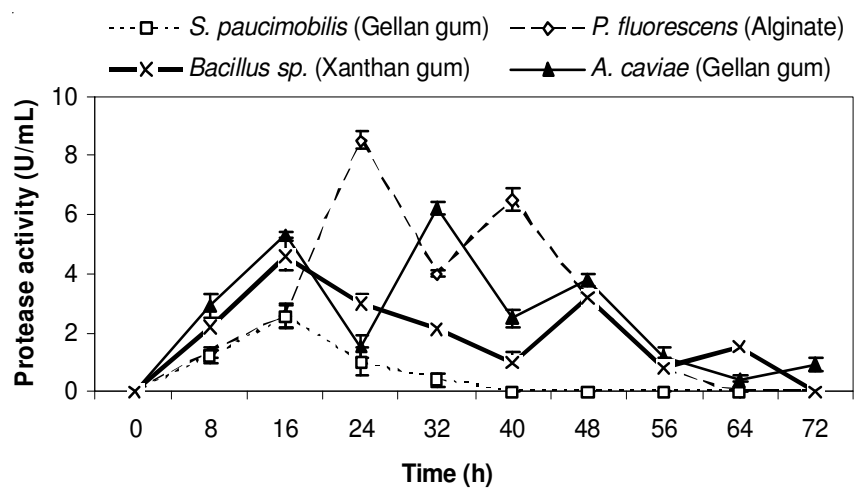

Fig. 2. Protease activities from bacteria cultures. Bars indicate standard deviations $(\mathrm{n}=3)$

Polysaccharide degrading activities: Polysaccharide degrading activities assayed in the culture supernatants taken along the $72 \mathrm{~h}$ cultures of the same 4 bacteria including as the same carbon sources are exhibited in Fig. 3(a), (b), (c) and (d). In addition to these, the best biofilm removal results are shown in Table-1.

Gellan lyase activities: Polysaccharide-degrading enzymes have been obtained from bacteria, fungi and bacteriophages. A few have been found in the same microbial species which produce the polysaccharide substrates ${ }^{32}$. Following the observation by Martins and Sa-Correia ${ }^{33}$ that several cultures of Sphingomonas spp. showed reduction in 
TABLE-1

BEST ENZYMATIC REMOVAL OF COOLING WATER SYSTEM BIOFILM USING BACTERIAL CULTURES

\begin{tabular}{|c|c|c|c|c|c|c|c|c|}
\hline \multirow{2}{*}{ Bacteria } & \multirow{2}{*}{ Substrate } & \multirow{2}{*}{$\begin{array}{l}\text { Time } \\
\text { (h) }\end{array}$} & \multicolumn{5}{|c|}{ Enzymatic activities $(\mathrm{U} / \mathrm{mL})^{*}$} & \multirow{2}{*}{$\begin{array}{l}\text { Percentage biofilm } \\
\text { removal* }\end{array}$} \\
\hline & & & Protease & Alginate lyase & Xylanase & Gellan lyase & Xanthan lyase & \\
\hline S. paucimobilis & Gellan gum & 32 & $0.4 \pm 0.2$ & $12 \pm 6$ & 0 & $132 \pm 10$ & 0 & $91 \pm 2$ \\
\hline Bacillus sp. & Xanthan gum & 16 & $4.6 \pm 0.5$ & 0 & $6.5 \pm 1.0$ & 0 & $9.5 \pm 1.2$ & $88 \pm 6$ \\
\hline P. fluorescens & Alginate & 40 & $6.5 \pm 0.4$ & $55 \pm 6$ & 0 & 0.08 & 0 & $75 \pm 5$ \\
\hline Bacillus sp. & Xylan & 40 & $1.0 \pm 0.3$ & 0 & $7.4 \pm 1.0$ & 0 & $2.0 \pm 0.9$ & $70 \pm 4$ \\
\hline S. paucimobilis & Alginate & 24 & $1.0 \pm 0.5$ & $48 \pm 4$ & 0 & $90 \pm 11$ & 0 & $62 \pm 3$ \\
\hline A. caviae & Gellan gum & 40 & $2.5 \pm 0.3$ & 0 & $0.9 \pm 0.2$ & $28 \pm 3$ & 0 & $45 \pm 7$ \\
\hline A. caviae & Xylan & 24 & $1.5 \pm 0.4$ & 0 & $2.5 \pm 1,2$ & 0 & 0 & $36 \pm 5$ \\
\hline P. fluorescens & Gellan gum & 24 & $8.5 \pm 0.3$ & $28 \pm 5$ & $1.28 \pm 0.9$ & $18 \pm 4$ & 0 & $25 \pm 3$ \\
\hline P. fluorescens & Xylan & 24 & $8.5 \pm 0.3$ & $28 \pm 5$ & $1.28 \pm 0.9$ & $18 \pm 4$ & 0 & $14 \pm 3$ \\
\hline
\end{tabular}

*Each value is an average of three replicates, \pm indicates standard deviation (SD) from mean value. $(\mathrm{p}<0.05$ for percentage biofilm removal).

the yield of exopolysaccharides on prolonged incubation, Sutherland and Kennedy ${ }^{32}$ reported the presence of a gellan lyase activity in some of the Sphingomonas spp. which synthesize gellan and related polymers. Similarly, in our study gellan lyase activity and bacterial growth was induced in S. paucimobilis by the presence of gellan gum as carbon source (Figs. 3b and 1b). Highest gellan lyase activity yield (132 \pm $10 \mathrm{U} / \mathrm{mL})$ and growth $(4.5 \pm 0.5 \mathrm{~g} / \mathrm{L})$ were obtained by $S$. paucimobilis cultures on gellan. Furthermore, maximal biofilm removal $(91 \pm 2 \%)$ was determined by S. paucimobilis cultures on gellan gum (Table-1). This percentage was quite high for removal of biofilm. In other two studies, maximal removal efficiences of $P$. fluorescens biofilm were reported by using three fungal strains as $19-84 \%{ }^{25}$ and by using several commercial enzyme preparations as $10-85 \%{ }^{26}$.

Kennedy and Sutherland ${ }^{34}$ described that a group of gram negative rods produced a gellan lyase acting on deacylated gellan, as in our study. Similarly, P. fluorescens, S. paucimobilis and $A$. caviae readily grew in gellan as carbon source and they produced gellan lyase activity, especially $S$. paucimobilis (Fig. 3b). Mikolajczak et al. ${ }^{35}$ showed an enzyme activity, also determined gellan lyase-like enzyme from a Bacillus sp.

Alginate lyase activities: In present study, some enzyme activities by cultures on various polysac charides, first reached
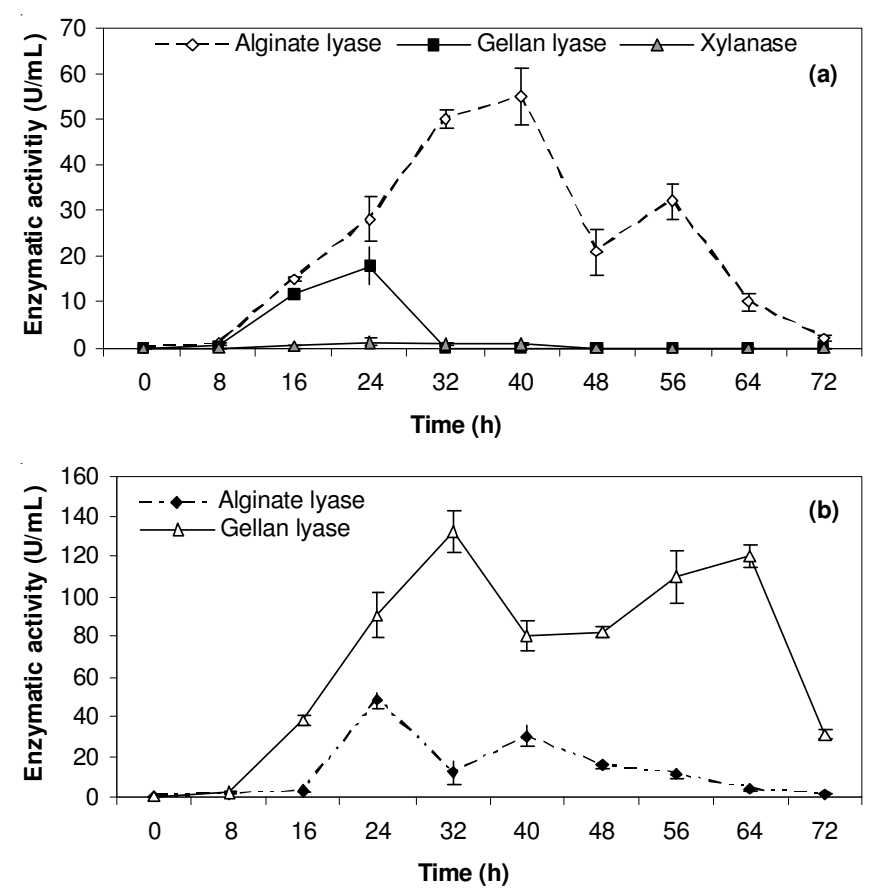
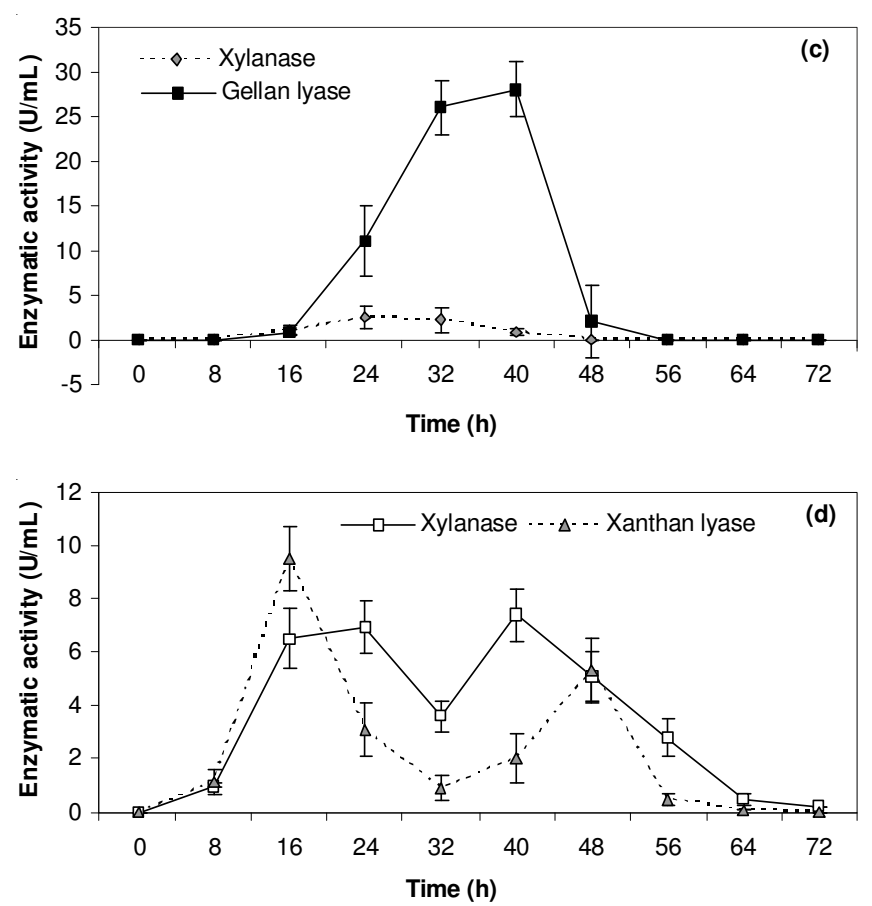

Fig. 3. Polysaccharide degrading activities from $P$. aeruginosa culture (a), S. paucimobilis culture (b), A. caviae culture (c), Bacillus sp. culture (d) Bars indicate standard deviations $(n=3)$

high ratios and then, decreased in a few hours before it increased again. As examples of this situation, alginate lyase activity by $P$. fluorescens (Fig. 3a) and S. paucimobilis (Fig. 3b), gellan lyase activity by $S$. paucimobilis culture (Fig. 3b), xanthan lyase activity in Bacillus sp. culture (Fig. 3d) and xylanase activity in Bacillus sp. culture (Fig. 3d). The reason of these secondary raises probably is that: first, bacteria produce polysaccharide degrading-enzyme by using the polysaccharide in medium as carbon source, then bacteria start to produce exopolysaccharides biofilm matrix material when polysaccharide substrate start to run out and later bacteria again produce enzyme to utilize it as polysaccharide substrate. Therefore, polysaccharases may therefore be produced to enable microorganisms to degrade polysaccharide substrates and utilize their component monomers as carbon and energy sources $^{36,37}$.

Xylan-degrading activities: Xylan is a ubiquitous polysaccharide, which comprises the major portion of hemicellulose found in the cell walls of plants. Xylan degrading enzymes are produced mainly by microorganisms ${ }^{28,38}$. A number of Bacillus strains capable of synthesizing the polysac- 
charides cellulose and xylan and related polymers were shown to possess constitutive cellulase and xylanase activity ${ }^{28,38}$.

Xylan from beech-wood was the carbon source providing better Bacillus sp. growth (maximum value of $5.22 \pm 0.2 \mathrm{~g} / \mathrm{L}$ ) (Fig. 1d) than A. caviae (maximum value of $2.95 \pm 0.4 \mathrm{~g} / \mathrm{L}$ ) (Fig. 1c) and $P$. fluorescens (maximum value of $2.0 \pm 0.2 \mathrm{~g} / \mathrm{L}$ ) (Fig.1a), probably as a result of the polysaccharide heterogeneity in the commercial product. Xylans contain arabinose, D-glucuronic acid and acetylated sugar units ${ }^{39}$. Due to its compositional complexity, a large number of enzymes have been observed to have some effect on xylan depolymerization $^{40}$, including endoxylanases, glucuronidases and acetyl esterases. In the study, the highest xylanase activity yields were also observed in Bacillus sp. (Fig. 3d). Lower xylanase activities were detected in A. caviae (max value of $2.5 \pm 1.2$ $\mathrm{U} / \mathrm{mL}$ ) (Fig. 3c) and P. fluorescens (max value of $1.28 \pm 0.9$ $\mathrm{U} / \mathrm{mL}$ ) (Fig. 3a) cultures than Bacillus sp. culture. A high level of both degrading activities, including xylanase activity, belong to Bacillus species known to produce a number of polysaccharide degrading and protein-degrading enzymes ${ }^{28,38}$.

Xanthan-degrading activities: In the study xanthandegrading activity was observed only in Bacillus sp. culture supernatant (Fig. 3d). Xanthan, the exopolysaccharides from Xanthomonas campestris strains, contains one molecule of D-glucuronic acid as the subterminal residue of a trisaccharide side-chain attached to cellobiose as a pentasaccharide repeat unit $^{41}$. The data with Bacillus sp. could also synthesize enzymes cleaving the side-chain sugars and leaving the cellulosic main chain of xanthan intact, as explained by Cadmus et $a l .^{42}$.

According to our results, the second-highest biofilm removal $(88 \pm 6 \%)$ was showed by Bacillus sp., when xanthan gum was used as carbon source in culture medium. This probably resulted from high protease activity $(4.6 \pm 0.5 \mathrm{U} / \mathrm{mL})$ (Fig. 2) registered in the same culture supernatant, which were efficient in removal of biofilm (Table-1). Another xanthandegrading bacterium Paenibacillus alginolyticus XL-1, isolated from soil, degrades approximately $28 \%$ of the xanthan molecule and appears to leave the backbone intact ${ }^{43}$. Also, xanthan were significantly degraded by microorganisms present in soil and human faeces ${ }^{44}$.

It was observed that increased numbers of alginatesynthesizing $P$. fluorescens cells caused increased expression of alginate lyase along growth (Fig. 1a and 3a). As the cells utilize alginate as a carbon source through expanded activity of alginate lyase against its substrate, this probably caused high cell numbers ${ }^{45}$.

In this study, the third-highest biofilm removal $(75 \pm 5 \%)$ was obtained by $P$. fluorescens cultured on alginate. Alginate lyase was also induced in $S$. paucimobilis culture by the presence of alginate (Fig. 3b), but at lower levels than $P$. fluorescens, with a maximum value of $48 \pm 4 \mathrm{U} / \mathrm{mL}$. In another study, the mass of alginates from $P$. fluorescens and $P$. putida fell approximately $50 \%$ per $24 \mathrm{~h}$ at $30^{\circ} \mathrm{C}$ in shaken cultures through the action of poly-D-mannuronate-specific lyases after cell growth had ceased ${ }^{46}$. The results with alginate lyase could also involve increased expression of the alginate lyase protein in mucoid strains of $P$. aeruginosa led to alginate degradation and accordingly to a considerable drop in the molecular mass and solution viscosity of this polymer, as observed by Boyd and Chakrabarty ${ }^{45}$. This resulted in enhanced sloughing of cells and detachment in Pseudomonas biofilm.

Previous data showed that biofilm bacterium Pseudomonas sp. was highly reduced (40\%) viscosity of exopolysaccharides of Burkholderia cepacia isolated from same cooling tower biofilm $^{47}$. Biofilms may allow to bacteria much greater polysaccharide-degrading and proteolytic activities than would be the case with planktonic bacteria.

\section{Conclusion}

In industrial settings, both the inactivation and removal of biofilms are of huge concern. Until nowadays, biofilm removal works were investigated the effects of commercial enzyme preparations for control of biofilms formed by several bacteria from various industries ${ }^{17,18,26}$ or from environmental source ${ }^{27}$. Studies on exopolysaccharides-synthesizing many bacteria have apparently totally successful to reveal the presence of enzymes degrading the exopolysaccharidess which they synthesize ${ }^{48}$. This study includes novelty regarding of enzymatic removal of biofilm and exopolysaccharides matrix of own producer bacteria in biofilm. Moreover, because the induction attempts were successful to produce high enzyme yields, these biofilm forming strains seem able to produce enzyme activities that can degrade bacterial biofilms to a significant extent.

The use of enzymes for removal of bacterial biofilm is still limited, partly due to the very low prices of chemicals in use. It is known that monocomponent enzymes can be used for removal of biofilm. However, the heterogeneity and complexity of the biofilm matrixmaterial limits the potential of monocompound enzymes ${ }^{49}$. This structure of biofilm matrix probably allows different alternatives for enzymatic removal strategy. As in present study, the use of culture supernatants obtained from habitant bacteria in biofilm and a mixture of carbohydrate-degrading enzyme activities in those supernatants may eliminate these limitations in enzymatic biofilm-removal treatment.

\section{ACKNOWLEDGEMENTS}

The authors thank Prof. Dr. Guven Ozdemir (Basic and Industrial Microbiology Section, Department of Biology, Faculty of Science, Ege University, Izmir, Turkey) for his guidance and help during the course of isolation and identification of the bacteria.

\section{REFERENCES}

1. D.G. Allison, Biofouling, 19, 139 (2003).

2. I. Turetgen and A. Cotuk, Environ. Monit. Assess., 125, 271 (2007).

3. W. Costerton, R. Veeh, M. Shirtliff, M. Pasmore, C. Post and G. Ehrlich, J. Clin. Invest., 112, 1466 (2003).

4. E. Denkhaus, S. Meisen, U. Telgheder and J. Wingender, Microchimica Acta, 158, 1 (2007).

5. H.C. Flemming, T.R. Neu and D.J. Wozniak, J. Bacteriol., 189, 7945 (2007).

6. J.R. Lawrence, G.D. Swerhone, U. Kuhlicke and T.R. Neu, Can. J. Microbiol., 53, 450 (2007).

7. I. Nikolaev and V.K. Plakunov, Microbiology, 76, 149 (2007).

8. J.B. Xavier and K.R. Foster, Proc. Nat. Acad. Sci. USA, 104, 876 (2007).

9. A. Brooun, S.H. Liu and K. Lewis, Antimicrob. Agents, 44, 640 (2000).

10. L. Zhang and T.F. Mah, J. Bacteriol., 190, 4447 (2008).

11. P. Phillips, E. Sampson, Q. Yang, P. Antonelli, A. Progulske-Fox and G. Schultz, Wound Heal Southern Africa, 1, 10 (2008). 
12. E. Sungur, I. Türetgen, R. Javaherdashti and A. Çotuk, Turk. J. Biol., 34, 389 (2010)

13. Y. Liu, W. Zhang, T. Sileika, R. Warta, N.P. Cianciotto and A. Packman, Biofouling, 25, 241 (2009)

14. T.R. Bott, Int. J. Chem. Eng., Article ID 619873 (2009).

15. G. Ozdemir and N. Ceyhan, Asian J. Chem., 22, 7393 (2010).

16. D.M. Grant and T.R. Bott, Heat Trans. Eng., 26, 44 (2005).

17. M. Augustin, T. Ali-Vehmas and F. Atroshi, J. Pharm. Pharmaceut. Sci., 7, 55 (2004)

18. Y. Lequette, G. Boels, M. Clarisse and C. Faille, Biofouling, 26, 421 (2010).

19. I.W. Sutherland, Microbiology, 147, 3 (2001).

20. S. Badel, C. Laroche, C. Gardarin, E. Petit, T. Bernardi and P. Michaud, Enzym. Microb. Technol., 48, 248 (2011).

21. I.W. Sutherland, FEMS Microbiol. Rev., 16, 323 (1995).

22. P. Watnick and R. Kolter, J. Bacteriol., 182, 2675 (2000).

23. S.L. Walker, M. Fourgialakis, B. Cerezo and S. Livens, J. Inst. Brew, 113, 61 (2007)

24. C. Johansen, P. Falholt and L. Gram, Appl. Environ. Microbiol., 63, 3724 (1997).

25. B. Orgaz, J. Kives, A.M. Pedregosa, I.F. Monistrol, F. Laborda and C. San Jos, Enzyme Microb. Tech., 40, 51 (2006).

26. I.P. Molobela, T.E. Cloete and M. Beukes, Afr. J. Microbiol. Res., 4, 1515 (2010).

27. C. Leroy, C. Delbarre, F. Ghillebaert, C. Compere and D. Combes, Biofouling, 24, 11 (2008).

28. L.N. Ten, W.T. Im, M.K. Kim and S.T. Lee, Lett. Appl. Microbiol., 40, 92 (2005).

29. A. Sahoo, N. Agarwal, D.N. Kamra, L.C. Chaudhary and N.N. Pathak, Anim. Feed. Sci. Tech., 80, 83 (1999).

30. R.M. Tomarelli, J. Charney and M.L. Harding, J. Lab. Clin. Med., 34, 428 (1949).
31. J.H. Priester, S.G. Olson, S.M. Webb, M.P. Neu, L.E. Hersman and P.A. Holden, Appl. Environ. Microbiol., 72, 1988 (2006).

32. I.W. Sutherland and L. Kennedy, Microbiology, 142, 867 (1996).

33. L.O. Martins and I. Sa-Correia, Biotechnol. Appl. Biochem., 20, 385 (1994).

34. J. Kennedy and I.W. Sutherland, Microbiology, 140, 3007 (1994).

35. M.J. Mikolajczak, L. Thorne, T.J. Pollock and R.W. Armentrout, Appl. Environ. Microbiol., 60, 402 (1994).

36. I.W. Sutherland, Carbohyd. Polym., 38, 319 (1999).

37. S.T. Lee and J.J. Lee, J. Microbiol. Meth., 29, 1 (1997).

38. L.N. Ten, W.T. Im, M.K. Kim, M.S. Kang and S.T. Lee, J. Microbiol. Meth., 56, 375 (2004).

39. W. Burchard, Light Scattering from Polysaccharides. In ed.: S. Dumitriu,

Polysaccharides, Structural Diversity and Functional Versatility, Marcel Dekker, New York, pp. 89-236 (2005).

40. J.A. Thompson, FEMS Microbiol. Rev., 104, 65 (1993).

41. I.W. Sutherland, J. Gen. Microbiol., 133, 3129 (1987).

42. M.C. Cadmus, L.K. Jackson, K.A. Burton, R.D. Plattner and M. Slodki, Appl. Environ. Microbiol., 44, 5 (1982).

43. H.J. Ruijssenaars, J.A.M. DeBond and S. Hartmans, Appl. Environ. Microbiol., 65, 2446 (1999).

44. H.J. Ruijssenaars, F. Stingele and S. Hartmans, Curr. Microbiol., 40, 194 (2000).

45. A. Boyd and A.M. Chakrabarty, Appl. Environ. Microbiol., 60, 2355 (1994).

46. E. Conti, A. Flaibani, M. O'Regan and I.W. Sutherland, Microbiol., 140, 1128 (1994).

47. N. Ceyhan and G. Ozdemir, Biofouling, 24, 129 (2008).

48. X. Zhang and P.L. Bishop, Chemosphere, 50, 63 (2003).

49. J.F. Frank, ASM Press, Washington, p. 101 (1997). 